\title{
Trends in obstetric emergency department attendance the first months of the coronavirus pandemic
}

\author{
Sahr Yambasu, Eve Gaughan \\ Department of Obstetrics, Rotunda Hospital, Dublin, Republic of Ireland
}

\begin{abstract}
Many medical disciplines reported a decline in patient attendance during the coronavirus pandemic. Our paper examines the effects that the coronavirus pandemic had on obstetric Emergency Department (ED) attendances in a tertiary maternity centre in the Republic of Ireland. A retrospective cross-sectional analysis was performed on administrative data regarding the number of obstetric patients attending the ED from January to July in 2019 and 2020. These numbers were compared to the number of reported coronavirus cases in Ireland as released in official government publications. A paired sample t-test was carried out to see if there was a significant difference in attendance in the obstetric ED in 2020 compared to in 2019. When COVID-19 cases peaked at 17,377 in April 2020, ED attendance showed their largest decline of $27 \%$. The cumulative decline in ED attendances from January to July in 2019 to 2020 was $13 \%$. However, this decline was not found to be statistically significant. In contrast to other disciplines,
\end{abstract}

Correspondence: Sahr Yambasu, Rotunda Hospital, Dublin, Republic of Ireland, D01P5W9. Tel.: +353862323279

E-mail: yambasus@tcd.ie

Key words: Coronavirus; obstetrics; emergency department; COVID-19.

Acknowledgements: The authors thank Dr Rishi Roopnarinesingh for his input to the study.

Contributions: SY extracted the data, performed the analysis and data interpretation and drafted the manuscript. EG is the guarantor for the study.

Conflict of interests: None. This work was not supported by any grant.

Availability of data and materials: All data generated or analyzed during this study are included in this published article.

Ethics approval and consent to participate: Research approval obtained from the Rotunda Hospital Research Advisory Group on the $19^{\text {th }}$ of May 2020. Reference: RAG-2020-011. The study is conformed with the Helsinki Declaration of 1964, as revised in 2013, concerning human and animal rights.

Received for publication: 15 December 2020.

Revision received: 16 April 2021.

Accepted for publication: 30 April 2021.

This work is licensed under a Creative Commons Attribution 4.0 License (by-nc 4.0).

${ }^{\circ}$ Copyright: the Author(s), 2021

Licensee PAGEPress, Italy

Emergency Care Journal 2021; 17:9562

doi:10.4081/ecj.2021.9562 the COVID-19 pandemic did not cause a decrease in obstetric ED attendance.

\section{Introduction}

The first case of COVID-19 in Ireland was confirmed on Saturday the $29^{\text {th }}$ of February. Partial lockdown was put into place on the $6^{\text {th }}$ of March and on the $27^{\text {th }}$ of March a full lockdown was imposed nationwide restricting all non-essential activities.

The effect that these restrictions had on healthcare services were significant. Hospitals saw a dramatic change in the type of attendances. Non-essential clinics and elective surgeries were cancelled. Visiting restrictions were put in place. Emergency Departments (EDs) were still open, but patients were encouraged to attend only if necessary. This led to a decline in ED attendance rates.

In Irish public hospital EDs, this was reflected by $45.4 \%$ fewer attendances on the week ending on the $29^{\text {th }}$ of March in comparison to the week ending on the $1^{\text {st }}$ of March when the pandemic was just beginning. ${ }^{1}$ One urban hospital in the United Kingdom (UK) found that ED attendances decreased by more than half $(51.7 \%)$ during lockdown. During this period the rate of patients attending the ED that required admission rose from $17.3 \%$ to $24.0 \%$, with $4 \%$ requiring direct admission to the intensive care unit (as compared to $1 \%$ prior to lockdown). ${ }^{2}$

A similar clinical picture was seen in North America. One cross-sectional study of 24 EDs across five states in North America found that the pandemic caused a decrease in visits ranging from $41.5 \%$ to $63.5 \%{ }^{3}$

Specialist EDs also saw diminished numbers. The number of paediatric ED attendances in two British hospitals decreased by $30.4 \%$ in March $2020 .{ }^{4}$ An Italian study encompassing 15 hospitals noted that the rate of patients attending with acute coronary syndrome decreased from 18.9 admissions per day in 2019 (incidence rate ratio $0.70 ; 95 \% \mathrm{CI} 0.63-0.78 ; \mathrm{p}<0.001)$ to 13.3 admission per day in 2020.5

Worldwide, the coronavirus pandemic had far reaching effects on hospital attendance throughout many different specialties. This paper aims to examine the extent to which the obstetric ED was affected by increasing cases of COVID-19.

\section{Materials and Methods}

\section{Study design, setting and population}

Data was collected in a tertiary maternity hospital in Dublin in the Republic of Ireland. This hospital has a catchment area of 1 million people throughout 6 different counties. In 2019, care was provided to 10,200 mothers and 8,410 babies were delivered. A retrospective crosssectional analysis of prospectively collected administrative data from the months of January to July in the years of 2019 and 2020 was per- 
formed. Obstetric patients of any gestation that attended the ED during their pregnancy were included. This information was compared to the monthly numbers of coronavirus cases as recorded by the Irish government in official daily briefings. ${ }^{6,7}$

\section{Variables and data sources}

Anonymised administrative data on obstetric ED attendance in January to July 2019 and January to July 2020 was obtained. 21,985 attendances were analysed in total. This data contained information on the number of obstetric patients that attended the ED each month. Other patient variables were not included as part of this study.

\section{Data analysis}

To examine the differences between the two periods, we performed a paired sample t-test comparing ED attendances in 2019 to 2020. A p value of less than 0.05 was considered statistically significant.

\section{Results}

The catchment area covered by our hospital accounted for a significant proportion of cases of coronavirus. The total number of cases recorded in this area in the six month period observed was 16,727 , which comprised of $66 \%$ of all cases recorded in the Republic of Ireland in that period $(n=25,474$, Table 1, Figure 1).

The data was collected from the hospital ED for the first six months of both 2019 and 2020 (January to June). The overall drop in obstetric emergency department attendances from 2019 to 2020 was 1,557 , a drop of $13 \%$ (Table 2). This is despite the numbers of babies $>500 \mathrm{~g}$ delivered in the months of January to July remaining stable at 3,949 in 2019 compared to 4,028 in 2020. Data was analysed to see whether the change in the number of people attending the hospital emergency department was statistically significant. Appendix 1 shows that there are no missing values in the data and all of the observations are valid. Test of normality was conducted to see whether the data was normally distributed or not. Appendix 2 shows that in $2019 \mathrm{p}>0.05$ and in $2020 \mathrm{p}>0.05$. This indicates that the data was normally distributed.

Figure 2 and Figure 3 shows that in the years 2019 and 2020 there are no outliers in the data. The sample size is small, but as the data is normally distributed and there are no significant outliers, we proceeded with the further inferential analysis. A paired sample t-test was carried out to see if there was a significant difference in attendance of the people in hospital emergency department in 2020 compared to in 2019.

Table 3 shows that in 2019, the average attendance ( $M=1946.83, S D=37.10$ ) was greater than the average attendance in Year $2020(M=1717.33, S D=168.24)$.

Table 4 shows that there is insignificant positive weak correlation between 2019 and 2020. $\mathrm{r}=0.266, \mathrm{p}=0.611$.

Table 5 shows the paired sample statistics. Attendance in 2020 compared with attendance in 2019 was statistically insignificant $t$ $(5)=2.168, p=0.082$. Hence, we accept the null hypothesis and can conclude that there is no significant difference in people attending the emergency department in 2020 compared to 2019.

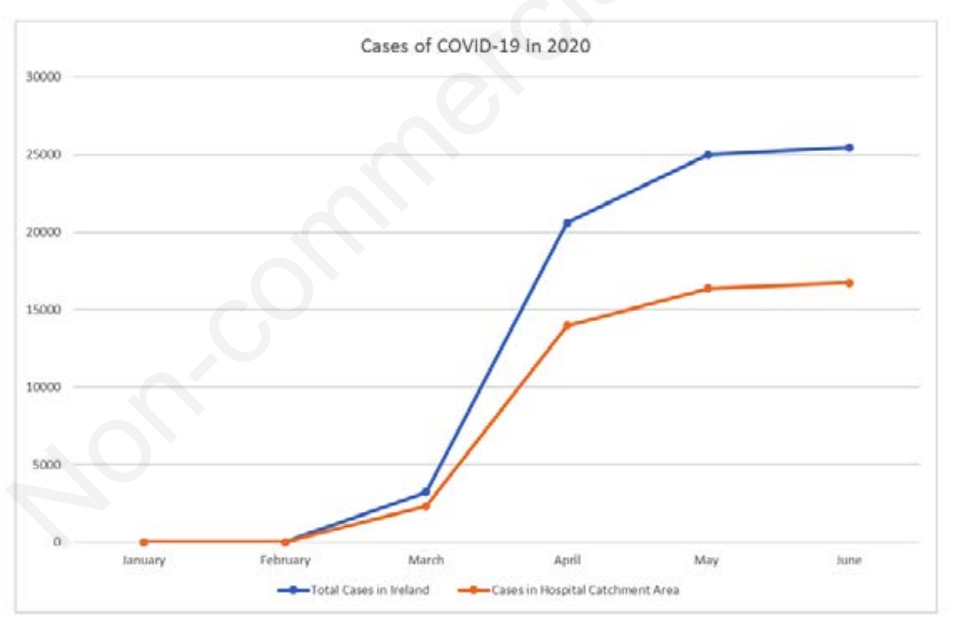

Figure 1. Officially reported COVID-19 cases in Ireland (2020).

Table 1. Officially reported COVID-19 cases (2020).

\begin{tabular}{lcccccccc} 
& January & February & March & April & May & June & Total \\
Cases in hospital catchment area & 0 & 1 & 2328 & 11631 & 2423 & 344 & 16727 \\
Total cases in Ireland & 0 & 1 & 3234 & 17377 & 4378 & 484 & 25474 \\
\hline
\end{tabular}

Table 2. Obstetric emergency department attendances from Jan-Jun 2019 vs. Jan-Jun 2020.

\begin{tabular}{ccccccccc} 
& January (\%) & February (\%) & March (\%) & April (\%) & May (\%) & June (\%) & Total (\%) \\
2019 & 2049 & 1795 & 1985 & 1904 & 2013 & 1935 & 11861 \\
2020 & 2159 & 1821 & 1507 & 1390 & 1678 & 1749 & 10,304 \\
& $+110(+5.4)$ & $+26(+1.4)$ & $-478(-24.1)$ & $-514(-27)$ & $-335(-16.6)$ & $-186(-9.6)$ & $1557(13)$ \\
\hline
\end{tabular}




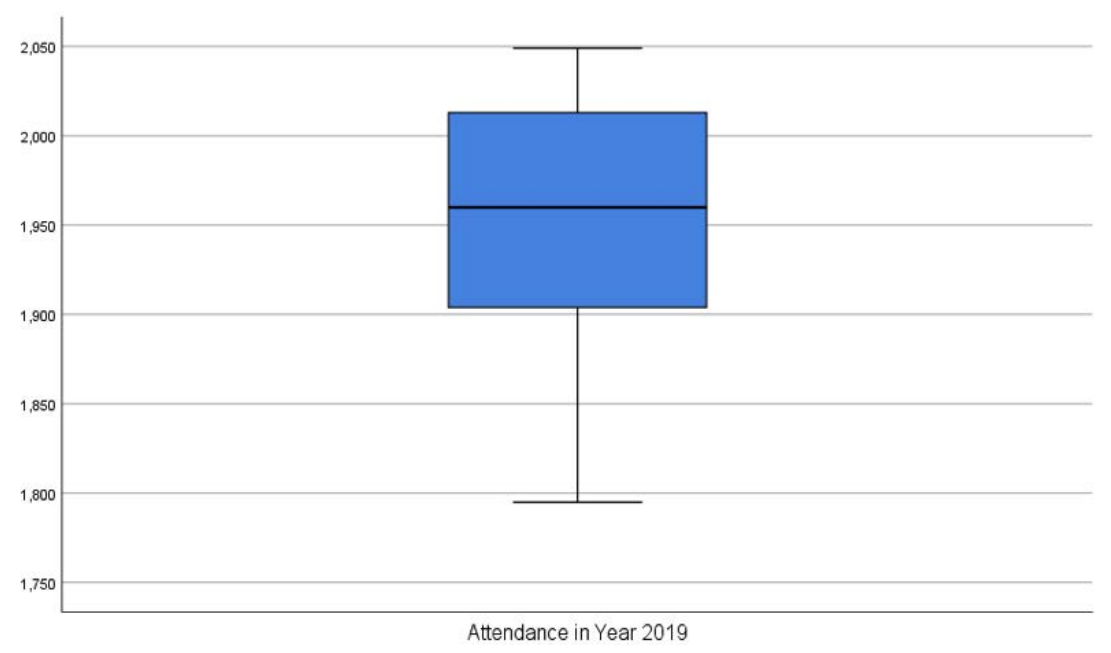

Figure 2. Attendance in year 2019.

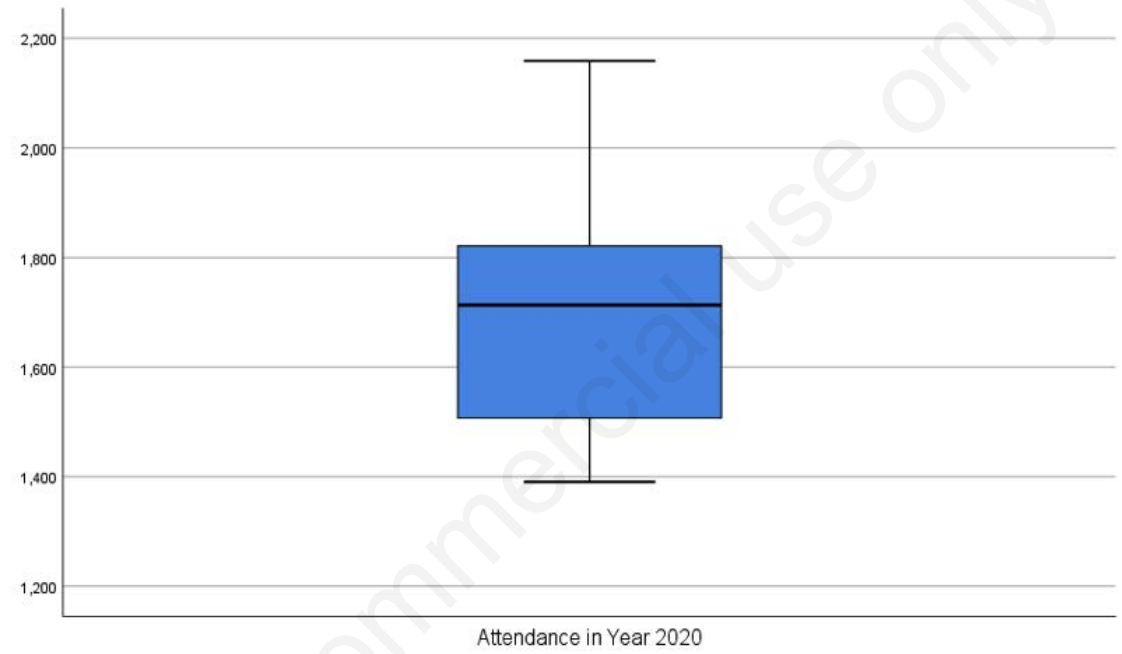

Figure 3. Attendance in year 2020.

Table 3. Paired samples statistics.

\begin{tabular}{ccccccc} 
& & Mean & N & Std. Deviation & Std. Error Mean \\
Pair 1 & Attendance in year 2019 & 1946.83 & 6 & 90.885 & 37.104 \\
& Attendance in year 2020 & 1717.33 & 6 & 268.236 & 109.507 \\
\hline
\end{tabular}

Table 4. Paired samples correlations.

\begin{tabular}{llllll} 
& N & Correlation & & Sig. \\
Pair 1 & Attendance in year 2019 \& Attendance in year 2020 & 6 & 0.266 & 0.611 \\
\hline
\end{tabular}

Table 5. Paired samples test.

\begin{tabular}{|c|c|c|c|c|c|c|c|c|c|}
\hline & & \multirow[t]{2}{*}{ Mean } & \multirow[t]{2}{*}{$\begin{array}{c}\text { Std. } \\
\text { deviation }\end{array}$} & \multirow[t]{2}{*}{$\begin{array}{l}\text { Paired differences } \\
\text { Std. error } \\
\text { mean }\end{array}$} & \multicolumn{3}{|c|}{$\begin{array}{l}95 \% \text { confidence interval } \\
\text { of the difference }\end{array}$} & \multirow[t]{2}{*}{ df } & \multirow[t]{2}{*}{ Sig. (2-tailed) } \\
\hline & & & & & Lower & Upper & $\mathrm{t}$ & & \\
\hline Pair 1 & $\begin{array}{l}\text { Attendance in } \\
\text { year } 2019 \text { - attendance } \\
\text { in Year } 2020\end{array}$ & 229.500 & 259.328 & 105.870 & -42.648 & 501.648 & 2.168 & 5 & .082 \\
\hline
\end{tabular}




\section{Discussion}

Our results indicate that the decreased number of obstetric patients attending the ED during the coronavirus pandemic was not statistically significant. The pandemic and its associated lockdown did not impact our obstetric ED to the extent that other specialties have been affected.

A concern associated with pandemic situations is that patients with valid concerns may be discouraged from attending the ED due to their fear of contracting the virus. During the coronavirus pandemic, general emergency departments in Ireland reported a decline of $27 \%$ in cases classified as very urgent/immediate. Less urgent attendances were also found to have declined by $32 \% .{ }^{1}$ If these numbers were replicated in our obstetric ED, this would likely impact maternofoetal health in a significant way.

Poor antenatal attenders of maternity services have a higher rate of perinatal mortality. They also exhibit higher proportions of birth weights $<2500 \mathrm{~g}$, babies born before 37 weeks gestation and babies requiring admission into the special care baby unit (SCBU) ${ }^{8}$ Other adverse pregnancy outcomes associated with poor antenatal attendance include chorioamnionitis, placental abruption and neonatal death. ${ }^{9}$

Our hospital took steps to educate obstetric patients about potential red flag symptoms that require hospital attendance and create clear pathways for women to attend hospital. A telephone hotline was staffed by healthcare professionals $24 / 7$ to provide advice to those who were unsure if their symptoms warranted hospital attendance. Rapid triage and assessment to minimise time in hospital as well as adequate social distancing measures were also implemented to minimise the risk of exposure to coronavirus for those patients that needed to attend hospital. These steps may have played a role in ensuring that obstetric ED attendances did not decrease significantly.

One would expect that the pandemic would decrease nonurgent attendances, as patients with less urgent complaints would be deterred due to the fear of contracting the virus. Around $15 \%$ of attendances to general EDs are for non-urgent reasons..$^{10}$ The numbers of non-urgent attendances appear to be higher in the obstetric population, with up to $84 \%$ of pregnant women receiving emergency care at some point during their pregnancy and $35.6 \%$ of these patients having at least one visit to the ED that is classified as nonurgent. ${ }^{11}$

Without examining the type of presentations that caused people to attend the ED, as well as the severity of these presentations, it is impossible to say whether non-urgent ED attendances decreased during the pandemic. This highlights a limitation of this study. The absence of data on the reasons why patients attended the ED in the periods before and after the pandemic makes it difficult to comment on whether or not the ratio of urgent to non-urgent attendances changed or remained the same.

\section{Conclusions}

Despite a decreased attendance in response to the COVID-19 pandemic in many disciplines throughout the world, this was not replicated in our obstetric ED. Pathways put in place by our hospital created an effective route through which those with valid concerns were able to attend and this may have helped to prevent a significant decline. However, examining the reasons for ED attendance would provide valuable information as to whether the demographic of those attending changed during the pandemic.

\section{References}

1. Brick A, Walsh B, Keegan C, Lyons S. COVID-19 and emergency department attendances in Irish public hospitals. Accessed 2020 Aug 20. Available from: https://doi.org/ 10.26504/qec2020may_SA_lyons

2. Honeyford K, Coughlan C, Expert P, et al. Changes in Emergency Department attendances before and after COVID19 lockdown implementation: a cross sectional study of one urban NHS Hospital Trust. MedRxiv 2020;2020.07.20. 20157560 .

3. Jeffery MM, D’Onofrio G, Paek H, et al. Trends in Emergency Department Visits and Hospital Admissions in Health Care Systems in 5 States in the First Months of the COVID-19 Pandemic in the US. JAMA Intern Med 2020;180:1328-33.

4. Isba R, Edge R, Jenner R, et al. Where have all the children gone? Decreases in paediatric emergency department attendances at the start of the COVID-19 pandemic of 2020. Arch Dis Childhood 2020;105:704.

5. De Filippo O, D'Ascenzo F, Angelini F, et al. Reduced rate of hospital admissions for ACS during Covid-19 outbreak in Northern Italy. N Engl J Med 2020;383:88-9.

6. Republic of Ireland Government. Updates on COVID-19 (Coronavirus) from April - June 2020. Accessed 2020 Aug 18. Available from: https://www.gov.ie/en/publication/72d92updates-on-covid-19-coronavirus-from-april-june-2020/

7. Republic of Ireland Government. Updates on COVID-19 (Coronavirus) since January 2020. Accessed 2020 Aug 18. Available from: https://www.gov.ie/en/publication/20f2e0updates-on-covid-19-coronavirus-since-january-2020/\#january-march

8. Blondel B, Dutilhb P, Delourb M, Uzanc S. Poor antenatal care and pregnancy outcome. Eur J Obstet Gynecol Reproduct Biol 1993;50:191-6.

9. Raatikainen K, Heiskanen N, Heinonen S. Under-attending free antenatal care is associated with adverse pregnancy outcomes. BMC Public Health 2007;7:268.

10. O'Keeffe C, Mason S, Jacques R, Nicholl J. Characterising non-urgent users of the emergency department (ED): A retrospective analysis of routine ED data. PLoS One 2018;13:e0192855.

11. Kilfoyle KA, Vrees R, Raker CA, Matteson KA. Nonurgent and urgent emergency department use during pregnancy: an observational study. Am J Obstet Gynecol 2017:181.e1-7. 